\title{
Arsenic trioxide inhibits tumor-induced myeloid-derived suppressor cells and enhances T-cell activity
}

\author{
QINGMIN GAO ${ }^{1,2^{*}}$, JINGWEI JIANG ${ }^{1,2^{*}}$, ZHAOHUI CHU ${ }^{1,2}$, HAO LIN $^{1,2}$, \\ XINLI ZHOU ${ }^{1,2}$ and XIAOHUA LIANG ${ }^{1,2}$ \\ ${ }^{1}$ Department of Oncology, Huashan Hospital, Fudan University; ${ }^{2}$ Department of Oncology, Shanghai Medical School, \\ Fudan University, Shanghai 200040, P.R. China
}

Received July 15, 2016; Accepted December 8, 2016

DOI: $10.3892 / \mathrm{ol} .2017 .5679$

\begin{abstract}
Myeloid-derived suppressor cells (MDSCs), one of the major orchestrators of the immunosuppressive network, are associated with immune suppression and considered a prime target for cancer immunotherapy. At present, various strategies have been explored to deplete and/or inactivate MDSCs in vivo. In this study, we investigated the effect of arsenic trioxide (ATO) on MDSCs derived from tumor-bearing mice. This study examined the in vitro and in vivo effects of ATO administration on MDSCs from C57/j mice bearing either the $\mathrm{B} 16$ or $\mathrm{H} 22$ tumor. The MDSCs were then characterized for phenotype, gene expression and function. Administration with ATO in vitro significantly induced MDSC differentiation, inhibited their proliferation and triggered apoptosis. Treatment with ATO in these murine tumor models significantly inhibited tumor growth and splenomegaly, decreased
\end{abstract}

Correspondence to: Dr Xiaohua Liang, Department of Oncology, Huashan Hospital, Fudan University, 12 Wulumuqi Zhong Road, Shanghai 200040, P.R. China

E-mail: xiaohua_liang1@163.com

*Contributed equally

Abbreviations: Arg-1, arginase 1; CTL, cytotoxic T lymphocyte; DC, dendritic cell; ELISA, enzyme-linked immunosorbent assay; ERK, extracellular signal-regulated kinase; FITC, fluorescein isothiocyanate; GAPDH or G3PDH, glyceraldehyde 3-phosphate dehydrogenase; GM-CSF, granulocyte-macrophage CSF; H\&E, hematoxylin and eosin; IL-10, interleukin-10; iNOS, inducible nitric oxide synthase; JAK or Jak, Janus kinase; MDSC, myeloid-derived suppressor cell; MEK, mitogen-activated protein kinase kinase; mRNA, messenger RNA; MLR, mixed leukocyte reaction; PI3K, phosphatidylinositol 3-kinase; RT-PCR, reverse transcription-polymerase chain reaction; STAT, signal transducer and activator of transcription; TGF- $\beta$, transforming growth factor- $\beta$; TNF- $\alpha$, tumor necrosis factor- $\alpha$

Key words: arsenic trioxide, myeloid-derived suppressor cells, signal transducer and activator of transcription $3, \mathrm{~T}$ cell, tumor immunity the percentages of MDSCs in the spleen, promoted their differentiation, reduced tumor necrosis factor- $\alpha$ and interleukin-10 levels and weakened the immune inhibition activity of MDSCs on T cells. In addition, we observed the underlying mechanism involved in the regulation of MDSCs by ATO, which included a panel of cytokines and signaling pathways. The findings showed the immunoregulatory effects of ATO by inducing apoptosis, promoting differentiation and inhibiting the function of MDSCs, suggesting that ATO has potential clinical benefit as it selectively attenuates MDSC-induced immunosuppression.

\section{Introduction}

In recent years, clinical approaches have included using the immune system against cancer to initiate or amplify a host response against advanced cancer (1). Reversion of immunosuppression is considered a component of existing immune-based cancer therapy. Myeloid-derived suppressor cells (MDSCs) and their biological functions have aroused interest regarding their therapeutic, predictive and prognostic roles in cancer (2). MDSCs are a heterogeneous population of immature haematopoietic cells that have a role in immune tolerance, tumor progression and metastasis (3). They consist of two major subsets, $\mathrm{CD} 11 \mathrm{~b}^{+} \mathrm{Ly} 6 \mathrm{G}^{+} \mathrm{Ly} 6 \mathrm{C}^{\text {low }}$ granulocytic and CD11b ${ }^{+}$Ly6G-Ly6 $\mathrm{C}^{\text {high }}$ monocytic cells, in mice. Granulocytic MDSCs (G-MDSCs) express high levels of reactive oxygen species (ROS) that induce T-cell apoptosis and nitrate T-cell receptors. Monocytic MDSCs (M-MDSCs) produce nitric oxide (NO) and block T cell proliferation $(4,5)$. A number of mechanisms were involved in the immunosuppressive function of MDSCs, such as the production of transforming growth factor- $\beta$ (TGF- $\beta$ ) and ROS, and the expression of inducible NO synthase (iNOS) and arginase-1 (Arg-1). The fate of MDSCs influences the efficacy of systemic chemotherapy. Agents, such as all-trans retinoic acid and vitamin D, have been studied regarding their inhibitory effects on the immunosuppressive actions of MDSCs, including favoring their differentiation, or inhibiting their expansion or their immunosuppression $(6,7)$.

Arsenic trioxide (ATO) is a natural extract of traditional medicine, currently used as the standard care for acute promyelocytic leukemias (APLs) in adults, as well as for some solid 
tumors in clinical trials $(8,9)$. Accumulating evidence have demonstrated that ATO is involved in antitumor effects by influencing multiple signal transduction pathways, resulting in diverse cell effects, including apoptosis induction, growth inhibition and promotion of differentiation by ATO (10-13). The immunomodulatory properties of ATO have been previously described (14). In colon tumor-bearing mice, low doses of ATO can delay solid tumor growth by depleting regulatory $\mathrm{T}$ cells (Tregs) through oxidative and nitrosative bursts (15). Although progress has been made in exploring ATO function in the host immune system, it remains unknown whether or how ATO modulates the differentiation and phenotypic switching of MDSCs. In the present study, the antitumor immunity of ATO and its underlying molecular mechanism were systematically investigated.

\section{Materials and methods}

Experimental mice and cells. Female C57/j mice were purchased from the Department of Laboratory Animal Science of Fudan University (Shanghai, China). All the animal experiments were carried out in accordance with an approved protocol for animal use and handling. Unless specified, the mice used in these experiments were 6-8 weeks of age. The study was approved by the Animal Ethics Committee of Fudan University Animal Center.

B16 cells, a type of mouse melanoma cell, were obtained from the Chinese Academy of Science. Hepatoma 22 (H22) cells, one of the most widely used mice transplanted tumor cell lines, were a gift from the Second Military Medical University (Shanghai, China). All the cells were cultured in RPMI-1640 (Invitrogen Life Technologies, Carlsbad, CA, USA) with $10 \%$ fetal bovine serum (FBS) enriched with $0.4 \mathrm{mmol} / \mathrm{l}$ of sodium pyruvate, $4 \mathrm{mmol} / \mathrm{l}$ of HEPES and antibiotics (penicillin and streptomycin).

In vivo murine cancer model experiments. In vivo experiments were performed as previously described (16). Briefly, $1 \times 10^{5} \mathrm{~B} 16$ and $1 \times 10^{6} \mathrm{H} 22$ cells were separated and injected into the flank of 8-week-old C57/j mice. Tumor growth was monitored by measuring the two-dimensional tumor size with a digital caliper. When tumor volumes reached $50-80 \mathrm{~mm}^{3}$, the mice were randomized into control and treatment groups, with 6 mice in each group. According to the safe drug dosage and our preliminary findings, ATO was administered by injection at $2 \mathrm{mg} / \mathrm{kg}$ for 10 days. Tumor surfaces were measured 3 times a week.

Isolation and culture of MDSCs. Mice with $\mathrm{B} 16$ or $\mathrm{H} 22$ tumor were sacrificed and spleens were harvested, dissociated, and the red blood cells were lysed in lysis buffer. MDSCs were purified using a mouse MDSC isolation kit according to the manufacturer's instructions (Miltenyi Biotec $\mathrm{GmbH}$, Bergisch Gladbach, Germany). The purified cells were used for other experiments. MDSCs were cultured in Dulbecco's modified Eagle's medium (DMEM) (Life Technologies) with $10 \%$ FBS enriched with $0.4 \mathrm{mmol} / \mathrm{l}$ of sodium pyruvate, $4 \mathrm{mmol} / \mathrm{l}$ of HEPES, and antibiotics (penicillin and streptomycin) in the Corning 3261 ultra-low attachment culture dishes (Corning Inc., Corning, NY, USA). Since MDSCs are incapable of survival without growth factor, granulocyte-macrophage CSF (GM-CSF) $(40 \mathrm{pg} / \mathrm{ml})$ was used to support cell viability and differentiation.

Flow cytometry. The phenotypic profiles of MDSCs, G-MDSCs, M-MDSCs, mature dendritic cells (mDCs), macrophages, Tregs, and cytotoxic T lymphocytes (CTLs) were analyzed by staining $1 \times 10^{5}$ cells with allophycocyanin (APC)-conjugated anti-CD11b (dilution, 1:200; cat. no. 553312), fluorescein isothiocyanate (FITC)-conjugated anti-Gr-1 (dilution, 1:200; cat. no. 553127), phycoerythrin (PE)-conjugated anti-CD11c (dilution, 1:200; cat.no.561356), anti-Ly6G (dilution, 1:200; cat. no.560601), peridinin-chlorophyll-protein (PerCP)-conjugated anti-Ly6C (dilution, 1:200; cat. no. 552093), anti-CD8 (dilution, 1:200; cat. no. 557750), FITC-conjugated anti-F4/80 (dilution, 1:200; cat. no. 565411), anti-CD80 (dilution, 1:200; cat. no. 560926), anti-CD4 (dilution, 1:200; cat. no. 553047), and PE-Cy7-conjugated anti-CD25 (dilution, 1:200; cat. no. 561780). The following corresponding isotype-matched controls were used: APC-IgG1, FITC-IgG1, FITC-IgG2a, PE-IgG2a and PE-IgG2b. All the antibodies were purchased from BD Pharmingen; eBioscience, Inc. (San Diego, CA, USA). Surface-labeled cells were analyzed using a FACSCalibur flow cytometer (BD Biosciences, Franklin Lakes, NJ, USA).

Cell proliferation analysis. MDSCs were plated in 96-well plates at $1 \times 10^{4}$ cells/well in complete medium with $10 \%$ FCS. The cells were incubated overnight at $37^{\circ} \mathrm{C}$, and the next day, ATO was added in complete growth media to a final concentration of $2 \mu \mathrm{mol} / 1$. The cells were incubated with test compounds at $37^{\circ} \mathrm{C}$ in complete growth medium, and cell numbers were quantified using a Cell Counting Kit-8 (CCK-8) (Dojindo Laboratories, Kumamoto, Japan) kit with a Synergy 2 microplate reader at various time-points according to the the manufacturer's instructions. The results were presented as the proliferation index relative to the control cells.

Cell cycle assays. MDSCs were plated at $2 \times 10^{5}$ cells/well in 6-well tissue culture plates in DMEM growth medium (10\% heat-inactivated FBS) overnight. Following serum starvation for $24 \mathrm{~h}$, the cells were cultured in complete medium supplemented with ATO for 24 or $48 \mathrm{~h}$, and then harvested and fixed in $75 \%$ ethanol at $4^{\circ} \mathrm{C}$ overnight. The cells were incubated with RNase $\mathrm{A}(10 \mathrm{mg} / \mathrm{ml})$ for $10 \mathrm{~min}$ at room temperature and DNA was stained with $50 \mathrm{mg} / \mathrm{ml}$ propidium iodide (PI) for at least $15 \mathrm{~min}$ at $37^{\circ} \mathrm{C}$. The DNA content was determined by flow cytometry using the FACSCalibur flow cytometer.

Apoptosis assays. Annexin V/7-AAD, 4'6-diamidino-2-phenylindole (DAPI): MDSCs were washed twice with cold PBS and prepared according to the manufacturer's instructions (Invitrogen Life Technologies). After staining for $15 \mathrm{~min}$ at room temperature with Annexin V and PI, the cells were analyzed by flow cytometry.

Mixed leukocyte reaction (MLR) assay. MDSCs $\left(3 \times 10^{4}\right)$ sorted from ATO-treated mice and control groups were administered with rapamycin. T cells $\left(3 \times 10^{4}\right)$ harvested from BALB/c $(\mathrm{H} 2 \mathrm{~d})$ mice by CD $90.2^{+}$microbeads were labeled with CFSE. Then MDSCs and T cells were co-cultured for $72 \mathrm{~h}$. The 
radioactivity $(\mathrm{cpm})$ was measured to quantify $\mathrm{CD}^{+}$cell proliferation using a flow cytometry kit. In addition, T-cell proliferation was measured using a CCK-8 kit.

Enzyme-linked immunosorbent assay (ELISA). Supernatant from the MDSCs isolated from tumor-bearing mice and then treated with ATO, were harvested. In addition, the serum from the ATO-treated and control mice was collected. The concentrations of tumor necrosis factor- $\alpha$ (TNF- $\alpha)$ and interleukin-10 (IL-10) in the supernatant or serum were determined in triplicate using commercial ELISA kits according to the manufacturer's instructions (eBioscience, Inc.).

Reverse transcription-polymerase chain reaction (RT-PCR) and quantitative real-time PCR. Target cells were homogenized in TRIzol reagent (Invitrogen Life Technologies) and total RNA was extracted. RT-PCR was used to determine relative quantities of messenger RNA (mRNA) (OneStep RT-PCR kit; Qiagen, Hilden, Germany) using 28 PCR cycles. The intensity of each band was then analyzed by IQ Mac v1.2 software and quantitated using $\beta$-actin as the internal control. The following oligonucleotides were produced: internal control $\beta$-actin, 5'-GTGACGTTGACATCCGTAAAGA-3' (sense) and 5'-GCCGGACTCATCGTACTCC-3' (antisense); mouse Bcl-xL, 5'-GCAGGTAGTGAATGAACTCTTTCGG-3' (sense) and 5'-CAGAACCACACCAGCCACAGTC-3' (antisense); mouse Bax, 5'-GGATGCGTCCACCAAGAAGC-3' (sense) and 5'-GGAGGAAGTCCAGTGTCCAGCC-3' (antisense); mouse TGF- $\beta$, 5'-CCGCAACAACGCCATCTATG-3' (sense) and 5'-CTCTGCACGGGACAGCAAT-3' (antisense); mouse VEGF, 5'-CTTGTTCAGAGCGGAGAAAGC-3' (sense) and 5'-ACATCTGCAAGTACGTTCGTT-3' (antisense); mouse iNOS, 5'-GTTCTCAGCCCAACAATACAAGA-3' (sense) and 5'-GTGGACGGGTCGATGTCAC-3' (antisense); mouse ROS, 5'-CCAACTGGGATAACGAGTTCA-3' (sense) and 5'-GAGA GTTTCAGCCAAGGCTTC-3' (antisense); mouse Arg-1, 5'-CTCCAAGCCAAAGTCCTTAGAG-3' (sense) and 5'-AGG AGCTGTCATTAGGGACATC-3' (antisense).

Protein extraction and western blot analysis. MDSCs were plated at $1 \times 10^{6}$ cells/well in 6-well plates (Falcon multiwell; Becton-Dickinson, Franklin Lakes, NJ, USA). The following day, the cells were treated with ATO in DMEM medium containing $10 \%$ FBS or $0.1 \%$ bovine serum albumin (BSA) at the times indicated in the experiment. After treatment, the cells were washed with cold PBS and lysed in the culture dishes using cell lysis buffer containing protease inhibitors. Cell extract was separated on polyacrylamide-SDS gels, transferred, and probed with signal transducer and activator of transcription 3 (STAT3) (cat. no. ab119352), p-STAT3 (cat. no. ab30647), AKT (cat. no. ab8805), p-AKT (cat. no. ab8933), mitogen-activated protein kinase kinase (MEK) (cat. no. ab32091), p-MEK (cat. no. ab96379), extracellular signal-regulated kinase (ERK) (cat. no. ab196883) and p-ERK (cat. no. ab65142) (all from Abcam, Cambridge, MA, USA) antibodies. The protein band, specifically bound to the primary antibody, was detected using an IRDye 800CW-conjugated secondary antibody (dilution, 1:1,000; cat. no. 456413; Molecular Probes, Carlsbad, CA, USA) and LI-COR imaging system (LI-COR Biosciences, Lincoln, NE, USA).

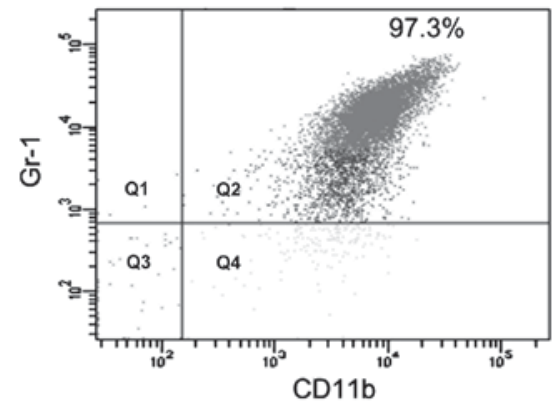

Figure 1. The purity of $\mathrm{CD}_{11} \mathrm{~b}^{+}$cells isolated from mouse MDSCs as tested using flow cytometry. MDSCs, myeloid-derived suppressor cells.

Statistical analysis. Statistical analyses were performed using GraphPad Prism, version 5.02 (Graphpad Software Inc., La Jolla, CA, USA). Data are presented as the mean \pm standard deviation (SD) from at least three independent experiments. The statistically significant differences between the groups were assessed using a one-tailed Student's t-test. $\mathrm{P}<0.05$ was considered to indicate a statistically significant difference. The degree of significance is indicated as: $\mathrm{P}<0.05, \mathrm{P}<0.01$ and $\mathrm{P}<0.001$.

\section{Results}

ATO induces MDSCs differentiation in vitro. The ability of ATO to induce the differentiation of MDSCs was evaluated. We collected MDSCs from the spleen of B16 tumor-bearing mice using the microbeads and the purity of CD11b+Gr- $1^{+}$cells was up to $95 \%$ (Fig. 1). Then we administered MDSCs with media alone or supplemented with 2 and $4 \mu \mathrm{M}$ ATO, respectively. The phenotypic appearance of MDSCs in cultures was analyzed $120 \mathrm{~h}$ later by flow cytometry. We found that the administration of ATO significantly reduced the proportion and absolute number of $\mathrm{CD} 11 \mathrm{~b}^{+} \mathrm{GR}-1^{+}$cells isolated from the spleen of tumor-bearing animals (Fig. 2A). Within the subsets, the M-MDSCs (CD11b+Ly6C ${ }^{+}$) were downregulated (Fig. 2B); only M-MDSCs are capable of differentiating into mature DC and macrophages in an in vitro environment (17). Additionally, in the presence of the ATO, the ratio of DCs $\left(\mathrm{CD} 11 \mathrm{c}^{+} \mathrm{CD} 40^{+}\right)$to macrophages $\left(\mathrm{F} 4 / 80^{+}\right)$was significantly upregulated compared to cells cultured in the absence of ATO (Fig. 2C and D), which indicates that ATO may induce M-MDSCs differentiation into mDCs and macrophages.

ATO inhibits proliferation and induces apoptosis of MDSCs in vitro. The results showed that ATO can inhibit the proliferation of MDSCs in vitro (Fig. 3A). We analyzed the effect of ATO on cell cycle distribution of MDSCs through flow cytometry, and the data showed a decrease in G2/M and significant G0/G1 cell cycle arrest in MDSCs exposed to ATO (Fig. 3B). To confirm that ATO induced cell death in vitro, the number of apoptotic and necrotic MDSCs was analyzed by flow cytometric detection of Annexin V and PI staining. We verified that ATO induced apoptosis in MDSCs (Fig. 3C). RT-PCR analysis revealed that the pro-survival protein Bcl-xL levels were significantly decreased while the pro-apoptotic protein Bax level was significantly increased in ATO-treated MDSCs compared to the control group (Fig. 3D). 
A
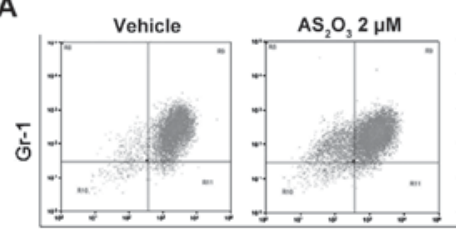

CD11b

B
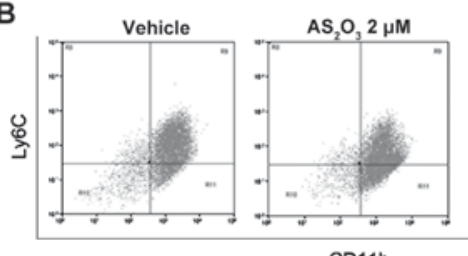

$\mathrm{CD} 11 \mathrm{~b}$

C

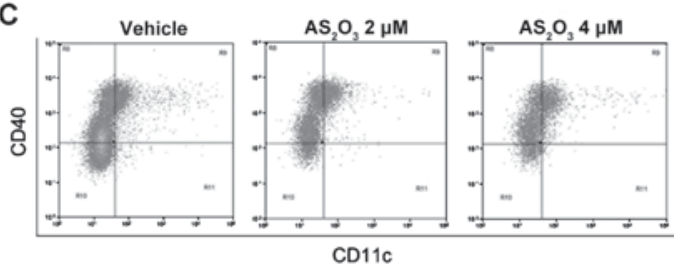

D

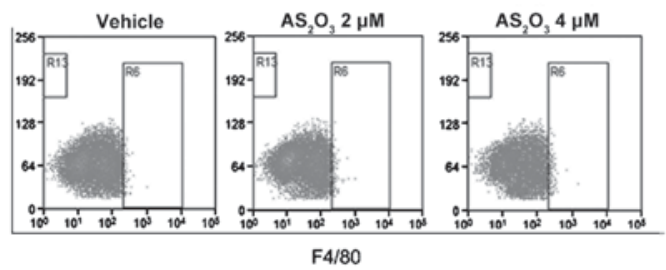

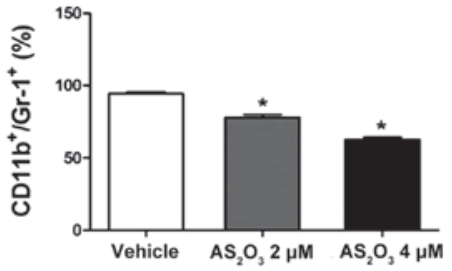
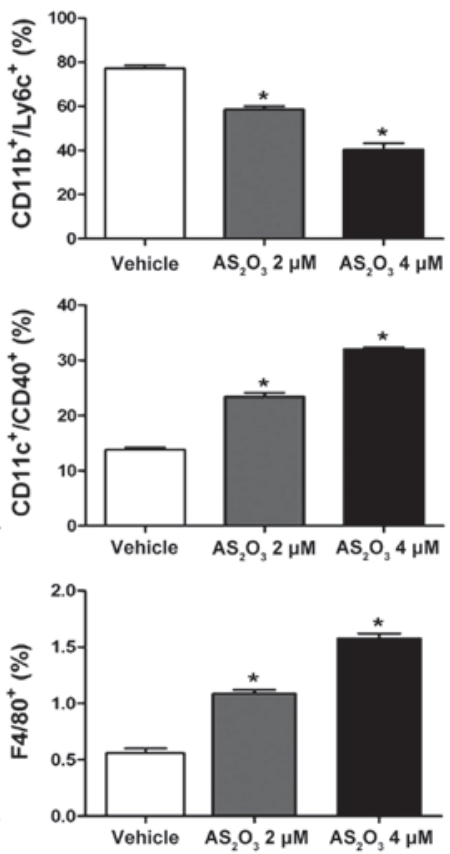

Figure 2. ATO induces differentiation of MDSCs in vitro. Sorted MDSCs collected from the spleen of B16 tumor-bearing mice were cultured in the presence of medium alone (control) or ATO $(2$ and $4 \mu \mathrm{M})$ for $120 \mathrm{~h}$, and the survival number of cells was calculated. (A) The CD11b $\mathrm{b}^{+} \mathrm{Gr}-1^{+} \mathrm{MDSCs}$, (B) CD11b $\mathrm{b}^{+} \mathrm{Ly} 6 \mathrm{C}^{+}$,

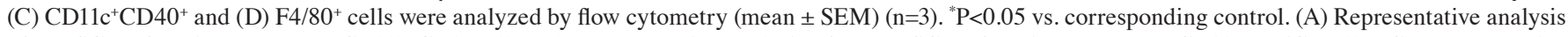
of MDSCs. R3 region represents CD11 ${ }^{+} \mathrm{Gr}-1^{+}$cells. (B) Representative analysis of M-MDSCs. R3 region represents CD11b $\mathrm{b}^{+} 6 \mathrm{C}^{+}$cells. (C) Representative analysis of DC. $\mathrm{R} 3$ region represents $\mathrm{CD} 11 \mathrm{C}^{+} \mathrm{CD} 40^{+}$cells. (D) Representative analysis of macrophage. $\mathrm{R} 6$ region represents $\mathrm{F} 4 / 80^{+}$cells. All the figures are representative of at least three independent experiments. ATO, arsenic trioxide; MDSCs, myeloid-derived suppressor cells; DC, dendritic cell.
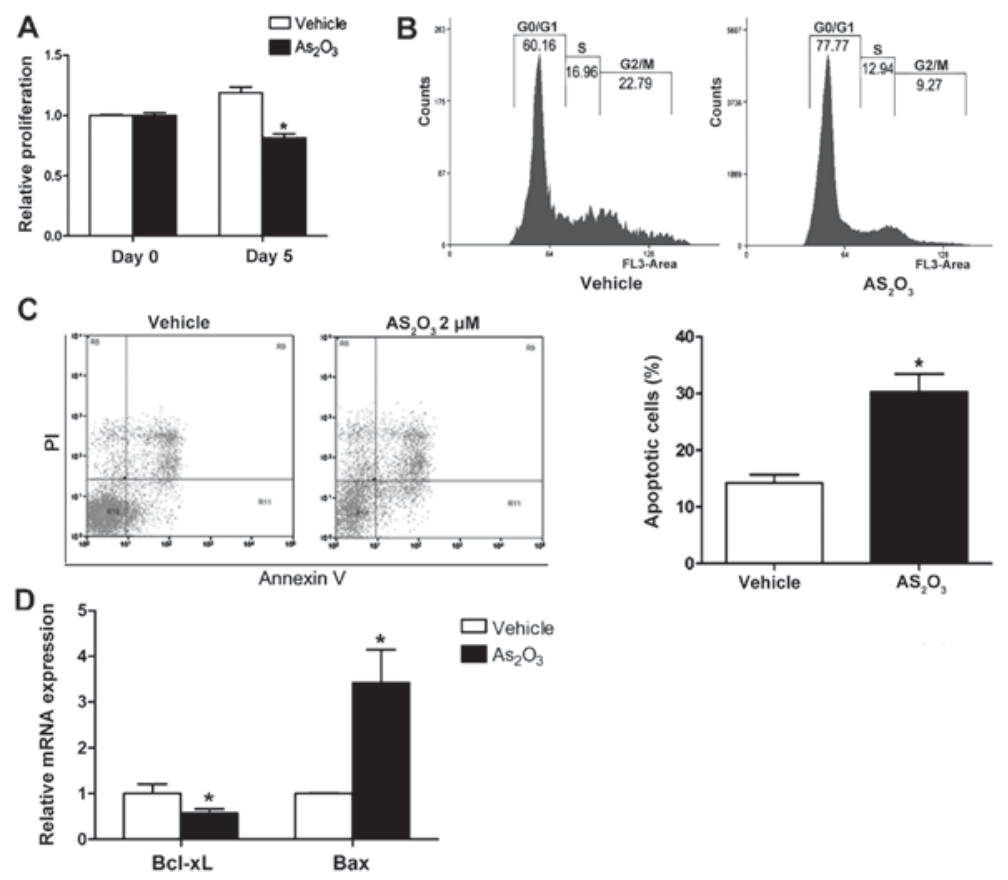

Figure 3. ATO inhibits proliferation and induces apoptosis of MDSCs in vitro. (A) Proliferation of MDSCs treated with vehicle or ATO ( $2 \mu \mathrm{M})$ for 5 days was evaluated by determining the cell viability with a CCK-8 assay. (B) Effect of ATO $(2 \mu \mathrm{M})$ for $48 \mathrm{~h}$ on cell cycle distribution was determined by flow cytometry. (C) Effect of ATO $(2 \mu \mathrm{M})$ on cell apoptosis in MDSCs treated for $48 \mathrm{~h}$. Cell apoptosis was measured with Annexin V staining. (D) Effect of ATO on mRNA expression of Bcl-xL and Bax in MDSCs. The results of three independent experiments are shown as the means \pm SEM. "P<0.05 vs. control. ATO, arsenic trioxide; MDSCs, myeloid-derived suppressor cells; CCK-8, Cell Counting Kit-8; mRNA, messenger RNA. 
A
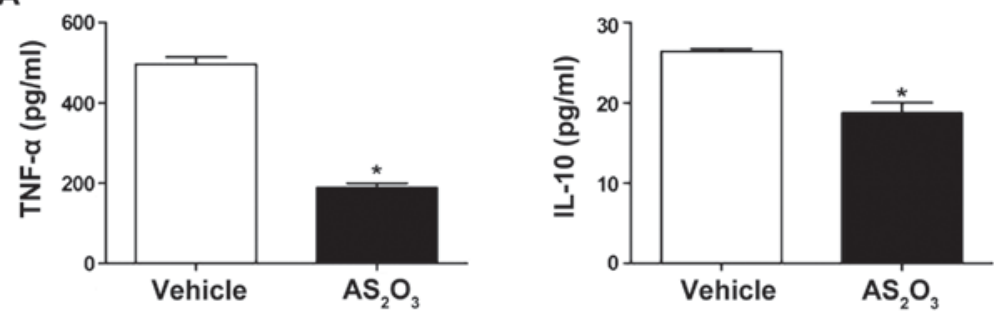

B

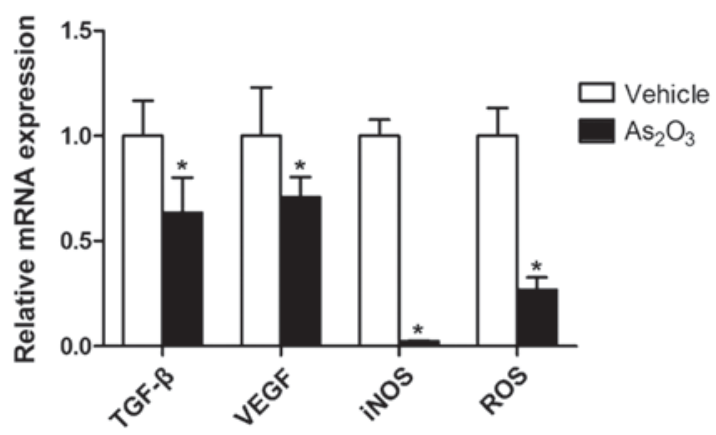

C

D

E
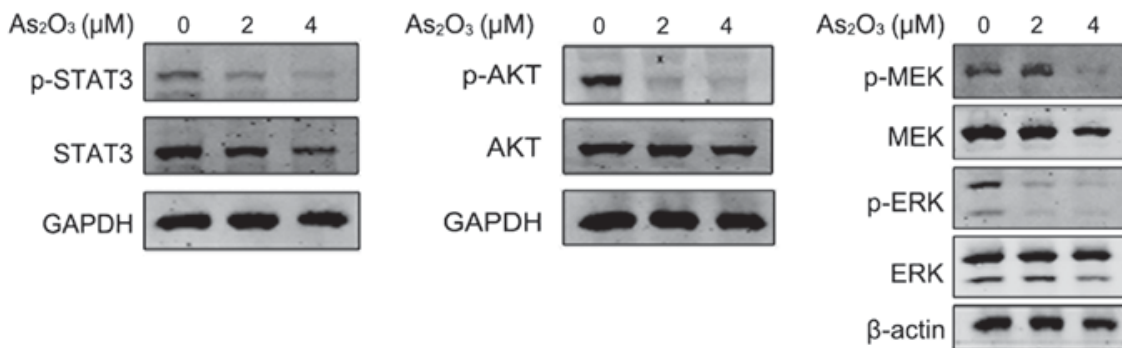

Figure 4. ATO regulates the function of MDSCs through JAK/STAT, PI3K/AKT and MEK/ERK signaling pathway in vitro. (A) The concentration of TNF- 0 and IL-10 in the supernatant from the MDSCs treated with medium alone (control) or ATO $(2 \mu \mathrm{M})$ for $120 \mathrm{~h}$ was measured by ELISA ("P<0.05). (B) Relative mRNA levels of TGF- $\beta$, VEGF, iNOS and ROS from MDSCs treated with ATO $(2 \mu \mathrm{M})$ for $48 \mathrm{~h}\left({ }^{*} \mathrm{P}<0.05\right)$. Histograms represent mean mRNA expression normalized to $\beta$-actin in each sample run in triplicate (mean $\pm \mathrm{SD}$ ). (C) The effect of ATO on JAK/STAT pathway activation was determined by western blot analysis of p-STAT3 in MDSCs. (D) The effect of ATO on PI3K/AKT pathway activation was determined by western blot analysis of p-AKT in MDSCs. (E) The effect of ATO on MEK/ERK pathway activation was determined by western blot analysis of p-MEK and p-ERK in MDSCs. ATO, arsenic trioxide; MDSCs, myeloid-derived suppressor cells; JAK, Janus kinase; STAT, signal transducer and activator of transcription; PI3K, phosphatidylinositol 3-kinase; AKT, serine/threonine-specific kinase; MEK, mitogen-activated protein kinase kinase; ERK, extracellular signal-regulated kinase; TNF- $\alpha$, tumor necrosis factor- $\alpha$; IL-10, interleukin-10; ELISA, enzyme-linked immunosorbent assay; mRNA, messenger RNA; TGF- $\beta$, transforming growth factor- $\beta$; iNOS, inducible nitric oxide synthase; ROS, reactive oxygen species.

ATO regulates the function of MDSCs through Janus kinase (JAK)/STAT, phosphatidylinositol 3-kinase (PI3K)/AKT and $M E K / E R K$ signaling pathway in vitro. The concentrations of TNF- $\alpha$ and IL-10 in supernatants from MDSCs administered with ATO tested by ELISA were downregulated compared to the vehicle group (Fig. 4A). In addition, the mRNA expression profiles were explored. RNA extracted from the MDSCs of the two groups detected by quantitative PCR showed that ATO significantly downregulated the expression of TGF- $\beta$, VEGF, iNOS and ROS in MDSCs (Fig. 4B), which play an important role in the suppressive activity of MDSCs.

To explore the potential mechanisms underlying the ATO-mediated inhibition of MDSCs, the key factor in the signaling pathway was investigated. Phosphorylation of STAT3, AKT, MEK and ERK were decreased in a dose-dependent manner by ATO (Fig. 4C-E), indicating that ATO may inhibit the function of MDSCs through the JAK/STAT, PI3K/AKT and MEK/ERK signaling pathway.
ATO induces MDSCs differentiation in vivo. An optimal antitumor drug should negatively target immunosuppressive cells while sparing immune effectors. B16 and H22 tumor-bearing mice suffered from splenomegaly and an increasing number of MDSCs. ATO effectively reduced the size and weight of the spleen in tumor-bearers (Fig. 5A and B). Consistently, we

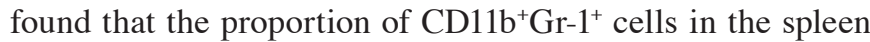
of the two treatment groups was significantly decreased compared to the saline-treated groups (Fig. 6A). The subsets of MDSCs demonstrated different changes in the B16 mice. The G-MDSCs (CD11b ${ }^{+}$Ly $6 c^{+}$Ly $6 G^{\text {high }}$ ) were reduced significantly while M-MDSCs $\left(\mathrm{CD} 11 \mathrm{~b}^{+} \mathrm{Ly}_{6 \mathrm{C}}{ }^{+} \mathrm{Ly}_{6 \mathrm{G}}{ }^{\text {low }}\right)$ showed no change (Fig. 6B, left). However, in the H22 mice, both the G-MDSCs and M-MDSCs were downregulated by ATO (Fig. 6B, right). Consistent with these results, the ratio of DCs, which expressed CD11c ${ }^{+} \mathrm{CD} 40^{+}$and $\mathrm{CD} 11 \mathrm{c}^{+} \mathrm{CD} 86^{+}$, were increasing (Fig. 6C). The results indicated that MDSCs could be induced into mDCs by ATO. 

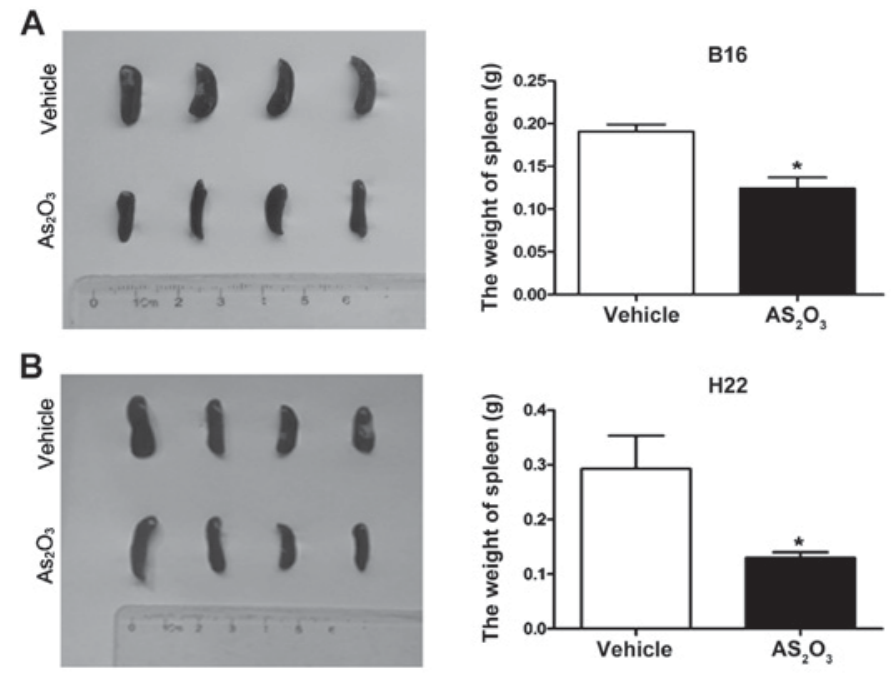

Figure 5. Spleen size and weight of B16 and H22 mice. (A) B16 mice treated with ATO for 10 days were sacrificed the second day. (Left) Image of representative isolated spleen showing different sizes. (Right) The weight of spleen (mean $\pm \mathrm{SD})(\mathrm{n}=10)$. One representative experiment of three is shown $\left({ }^{*} \mathrm{P}<0.05\right)$. (B) H22 mice treated with ATO for 10 days were sacrificed the second day. (Left) Image of representative isolated spleen showing different size. (Right) The weight of spleen (mean $\pm \mathrm{SD})(\mathrm{n}=10)$. One representative experiment of three is shown $(" \mathrm{P}<0.05)$. ATO, arsenic trioxide.
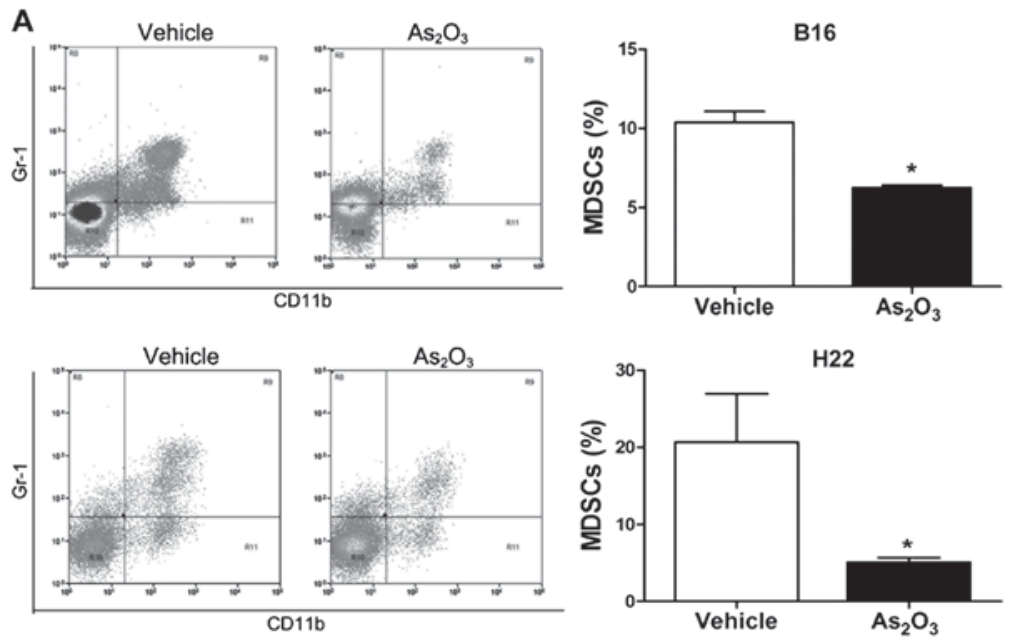

$$
\text { B }
$$

B16

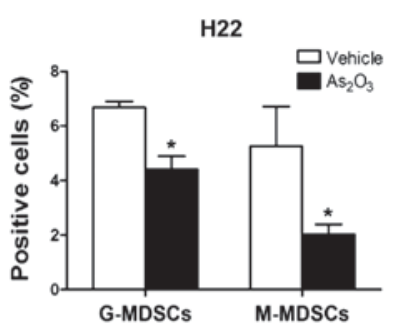

C

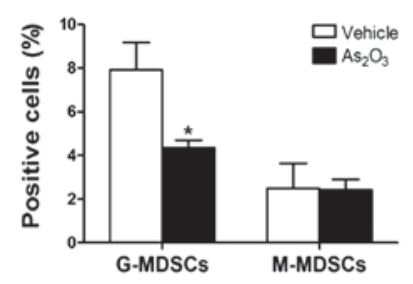

B16
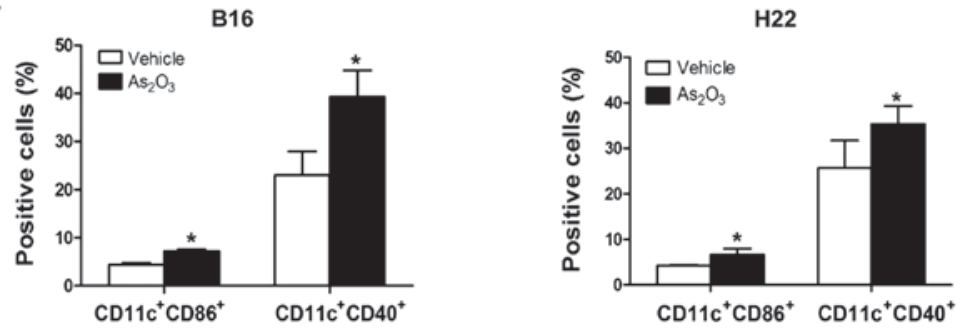

Figure 6. ATO promotes MDSCs differentiation in vivo. Sorted MDSCs harvested from the spleen of B16 and H22 tumor-bearing mice treated with saline and ATO $(2 \mathrm{mg} / \mathrm{kg})$ for 10 days, the survival number of cells was calculated and analyzed using flow cytometry (mean \pm SEM) (n=3). "P<0.05 vs. corresponding control. (A) Representative analysis of MDSCs. R3 region represents CD11b+Gr-1+ cells. (B) The ratio of M-MDSCs $\left(\mathrm{CD}^{+} 1 \mathrm{~b}^{+} \mathrm{Ly} 6 \mathrm{G}-\mathrm{Ly} 6 \mathrm{C}^{\mathrm{high}}\right)$ and G-MDSCs $\left(\mathrm{CD} 11 \mathrm{~b}^{+} \mathrm{Ly} 6 \mathrm{G}^{+} \mathrm{Ly} 6 \mathrm{C}^{\text {low }}\right)$ were analyzed using flow cytometry. (C) The ratio of mDCs $\left(\mathrm{CD} 11 \mathrm{c}^{+} \mathrm{CD} 86^{+}\right.$and $\left.\mathrm{CD} 11 \mathrm{c}^{+} \mathrm{CD} 40^{+}\right)$was analyzed using flow cytometry. ATO, arsenic trioxide; MDSCs, myeloid-derived suppressor cells; mDCs, mature dendritic cells. 

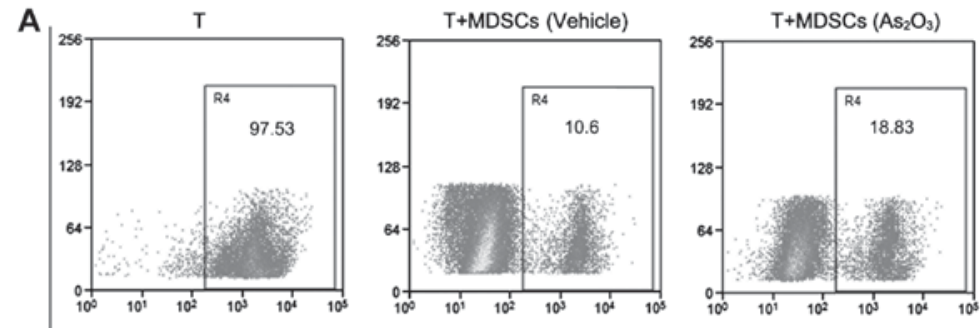

CFSE

B

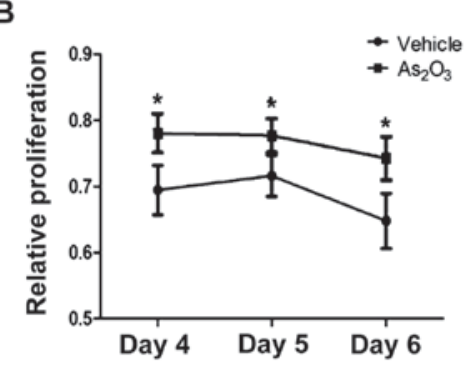

C

D
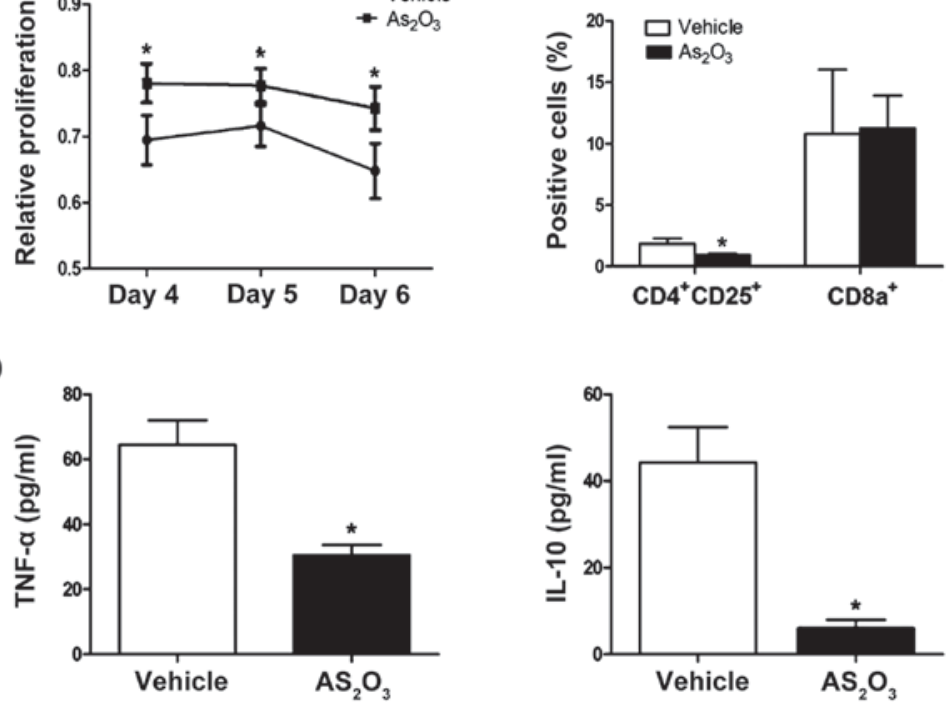

Figure 7. ATO impairs MDSCs immunosuppressive function. (A) MDSCs isolated from untreated or ATO-treated H22 mice were incubated for 5 days with CFSE-labeled naive T cells (MDSCs: T cell ratio=1:2). Effects of MDSCs on CFSE expression by gated CD4 $4^{+}$lymphocytes. (B) Proliferation of T lymphocytes co-cultured with MDSCs isolated from untreated or ATO-treated B16 mice was evaluated by determining the cell viability using a CCK-8 assay. (C) The ratio of regulatory $\mathrm{T}$ cells $\left(\mathrm{CD} 4{ }^{+} \mathrm{CD} 25^{+}\right)$and cytotoxic $\mathrm{T}$ lymphocytes $\left(\mathrm{CD}^{+} \mathrm{a}^{+}\right)$in the spleen of untreated or ATO-treated B16 mice was analyzed using flow cytometry. (D) The concentration of TNF- $\alpha$ and IL-10 in the serum of B16 mice treated with saline and ATO was measured by ELISA. The results of three independent experiments are shown as the means \pm SEM. "P $<0.05$ vs. control. ATO, arsenic trioxide; MDSCs, myeloid-derived suppressor cells; CCK-8, Cell Counting Kit-8; TNF- $\alpha$, tumor necrosis factor- $\alpha$; IL-10, interleukin-10; ELISA, enzyme-linked immunosorbent assay.

ATO impairs MDSCs immunosuppressive function. A distinct hallmark of MDSCs is their ability to inhibit the activation and proliferation of $\mathrm{T}$ cells. We further assessed the immune response of MDSCs by co-culturing the MDSCs and T cells from Balb/c mice. Consistent with previously reported results, MDSCs isolated from untreated tumor-bearing mice significantly inhibited $\mathrm{T}$ lymphocyte $\left(\mathrm{CD} 90.2^{+}\right.$) proliferation (18). The suppressive function of MDSCs isolated from ATO-treated tumor-bearing mice was significantly attenuated (Fig. 7A and B). In addition, the frequency of Tregs $\left(\mathrm{CD} 4{ }^{+} \mathrm{CD} 25^{+}\right)$, which is another important immunosuppressive cell subset, was also reduced in the ATO-treated mice. By contrast, ATO had practically no effect on the number of $\mathrm{CD}^{+}$cells (Fig. 7C). The secretion of TNF- $\alpha$ and IL-10 from serum harvested from the ATO-treated mice were downregulated (Fig. 7D). Therefore, ATO may be able functionally to reverse MDSC-mediated immune suppression.

ATO regulates the function of MDSCs through the JAK/ STAT, PI3K/AKT and MEK/ERK signaling pathways in vivo. We explored the underlying mechanism of residual MDSCs in the spleen of mice treated with ATO. Ten days after
ATO treatment, the mRNA levels of TGF- $\beta$, VEGF, iNOS, ROS and Arg-1 in MDSCs were decreased (Fig. 8A and B). Then, we further detected the conventional mediator underlying the regulation of MDSCs. The data show that the JAK/STAT, PI3K/AKT and MEK/ERK signaling pathways are involved in the inhibitory suppressor activity of MDSCs by ATO (Fig. 8C-E). Altogether, these results indicate that after ATO administration, MDSCs exhibit curtailed immunosuppressive activity through various signaling pathways.

\section{Discussion}

It is widely accepted that successful cancer immunotherapy can only be successful when associated with the elimination of suppressive cells (19). Our data have demonstrated that ATO has a cytotoxic effect, which is carried out targeting by MDSCs through induction of differentiation, suppression of proliferation, promotion of apoptosis, and inhibition of the immunosuppressive activity of MDSCs.

MDSCs derived from the expansion of myeloid precursor cells are defined as immature myeloid cells (iMCs), and they have impaired differentiation ability and potent immune suppressive activity (3). G-MDSCs and M-MDSCs in mice 
A

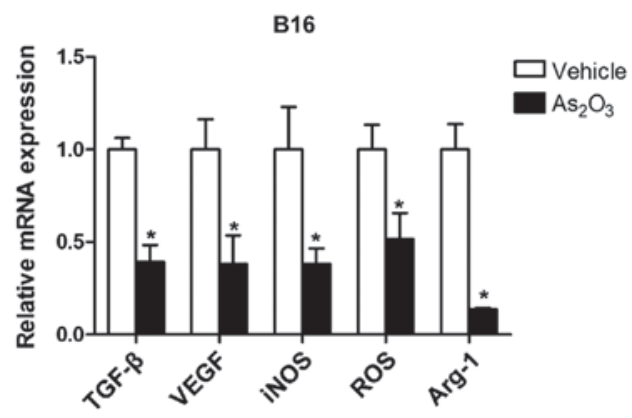

B
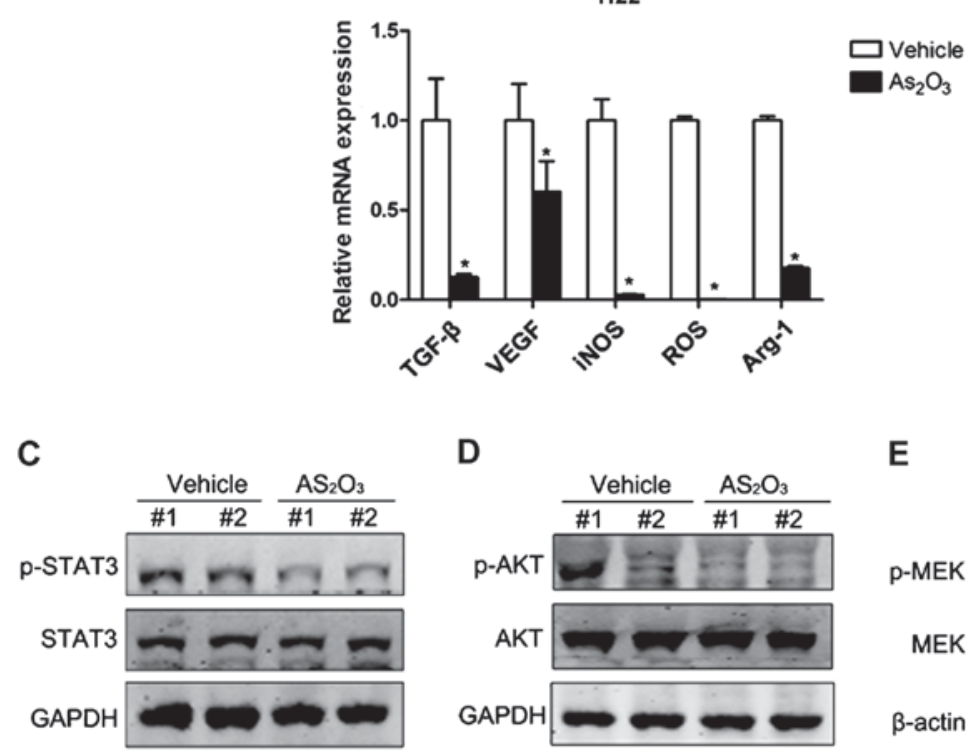

D

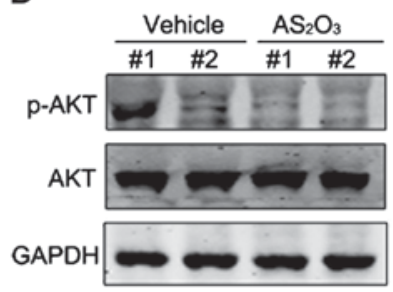

E

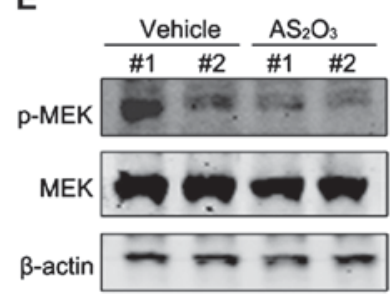

Figure 8. ATO regulates the function of MDSCs through the JAK/STAT, PI3K/AKT and MEK/ERK signaling pathways in vivo. (A) Relative mRNA levels of TGF- $\beta$, VEGF, iNOS, ROS and Arg-1 of MDSCs from untreated mice and ATO-treated B16 mice for 10 days ("P<0.05). Histograms represent mean mRNA expression normalized to $\beta$-actin in each sample run in triplicate (mean \pm SD). (B) Relative mRNA levels of TGF- $\beta$, VEGF, iNOS, ROS and Arg-1 of MDSCs from untreated mice and ATO-treated $\mathrm{H} 22$ mice for 10 days ( $\mathrm{P}<0.05$ ). Histograms represent mean mRNA expression normalized to $\beta$-actin in each sample run in triplicate (mean $\pm \mathrm{SD}$ ). (C) Extracts of MDSCs from the spleen of B16 mice treated with saline or ATO were analyzed by western blot analysis with antibodies against p-STAT3. (D) Extracts of MDSCs from the spleen of B16 mice treated with saline or ATO were analyzed by western blot with antibodies against p-AKT. (E) Extracts of MDSCs from the spleen of B16 mice treated with saline or ATO were analyzed by western blot with antibodies against p-MEK. ATO, arsenic trioxide; MDSCs, myeloid-derived suppressor cells; JAK, Janus kinase; STAT, signal transducer and activator of transcription; PI3K, phosphatidylinositol 3-kinase; AKT, serine/threonine-specific kinase; MEK, mitogen-activated protein kinase kinase; ERK, extracellular signal-regulated kinase; mRNA, messenger RNA; TGF- $\beta$, transforming growth factor- $\beta$; iNOS, inducible nitric oxide synthase; ROS, reactive oxygen species; Arg- 1 , arginase-1.

share the ability to suppress T-cell activation, albeit using distinct effector molecules and signaling pathways (20). In the differentiation in vitro experiment, M-MDSCs were able to differentiate into mDCs and macrophages while G-MDSCs were unable to further differentiate (21). Mouse mature DCs derived from myeloid precursor cells that express CD11c and the co-stimulator molecules CD80, CD86 and CD40, play a key role in the antigen-specific immune response $(22,23)$. However, the abnormal differentiation of myeloid cells leads to a curative defect in cancer $(24,25)$. In the present study, we found that ATO can promote MDSCs differentiation into $\mathrm{mDCs}$ both in vitro and in vivo.

The elevated presence of MDSCs in tumor bearers may be due to their elevated ability for proliferation and resistance to spontaneous apoptosis, when compared to those from tumor-free mice. In this study, we observed that ATO inhibits proliferation of MDSCs by triggering the G0/G1 arrest in cell cycle. In addition, the Bcl-2 family of the pro-apoptotic protein $\mathrm{Bax}$ and the anti-apoptotic protein $\mathrm{Bcl}-\mathrm{xL}$ retain a dynamic balance in the regulation of apoptosis of MDSCs (26). Our results demonstrate that the apoptosis of MDSCs induced by ATO may function by disturbing the balance in the expression between Bax and Bcl-xL.

The most important role of MDSCs is to suppress the function of $\mathrm{CD} 8^{+} \mathrm{T}$ cells (5). A range of molecular factors were involved in the immunosuppressive function of MDSCs, which leads to tumor evasion from host immune detection. TGF- $\beta$ together with iNOS produced by tumor-induced MDSCs may inhibit T-cell proliferation, while ROS and Arg-1 may suppress the $\mathrm{CD} 8^{+} \mathrm{T}$-cell response (27-30). Furthermore, TNF- $\alpha$ secreted by MDSCs can activate their suppressive activities and enhance the inhibition of lymphocyte proliferation (31). IL-10 can maintain the regulatory activity of Tregs and impair DC function $(32,33)$. In addition, MDSCs can suppress T-cell proliferation by inducing the development of Tregs (34). Our data show that ATO was able to effectively improve the proliferation of $\mathrm{T}$ cells by weakening the inhibitory factors of MDSCs. 
MDSCs modulate the tumor microenvironment favorable for angiogenesis and tumor progression through the expression of VEGF (35). In our study, the vascular-disrupting property of ATO that represses VEGF on MDSCs has been identified.

The JAK/STAT pathway has a critical role in cancer immunity, among which STAT3 has taken the lead $(36,37)$. STAT3 is the main transcription factor that regulates the function of MDSCs (38). The high phosphorylated STAT3 levels of MDSCs from tumor bearers correlates to Arg-1 and ROS production levels and activity, as well as the angiogenic gene VEGF expression (39-41). Additionally, the $\mathrm{PI} 3 \mathrm{~K} /$ serine/threonine-specific kinase (PI3K/AKT) signaling pathway is also responsible for the immune suppressive activity of MDSCs (42). The expansion of MDSCs may be triggered via ERK activation. Thus, it is clear that the MEK/ERK signaling pathway is a necessary supplement in the mediation of MDSCs (43). Therefore, we provide evidence that suppression of the JAK/STAT, PI3K/AKT and MEK/ERK signaling pathways is the potential mechanism underlying the regulation of MDSCs by ATO both in vivo and in vitro.

In conclusion, this study highlights that ATO plays immunotherapeutic interventions by curtailing the number of MDSCs, inhibiting their immunosuppressive activity and restoring the immunological surveillance. A recent study revealed that ATO combination with irinotecan therapy has an additive antitumor effect compared to control and irinotecan alone on account of its vascular damage feature (44). Our study identified that ATO is useful as a chemosensitizer that normalizes conditions in tumor microenvironment in combination therapy. We hope to provide new insight into modern cancer therapy and that clinical investigators may be encouraged to use ATO as a single agent or combination with additional chemotherapeutic agents in treating patients diagnosed with solid tumors.

\section{Acknowledgements}

The present study was supported by grants from the National Natural Science Foundation of China (nos. 81101551 and 81302010), Natural Science Foundation of Shanghai, China (no. 13ZR-1405000), the first session Funding Schemes for Young Doctor Training of Shanghai, China (no. 20120443) and the Project to Improve the Ability of Scientific Research for Young Teachers of Fudan University, China (no. 20520133345).

\section{References}

1. Drake CG, Lipson EJ and Brahmer JR: Breathing new life into immunotherapy: review of melanoma, lung and kidney cancer Nat Rev Clin Oncol 11: 24-37, 2014.

2. Diaz-Montero CM, Finke J and Montero AJ: Myeloid-derived suppressor cells in cancer: therapeutic, predictive, and prognostic implications. Semin Oncol 41: 174-184, 2014.

3. Talmadge JE and Gabrilovich DI: History of myeloid-derived suppressor cells. Nat Rev Cancer 13: 739-752, 2013.

4. Youn JI, Nagaraj S, Collazo M and Gabrilovich DI: Subsets of myeloid-derived suppressor cells in tumor-bearing mice. J Immunol 181: 5791-5802, 2008.

5. Gabrilovich DI and Nagaraj S: Myeloid-derived suppressor cells as regulators of the immune system. Nat Rev Immunol 9: 162-174, 2009.

6. Mirza N, Fishman M, Fricke I, Dunn M, Neuger AM, Frost TJ, Lush RM, Antonia S and Gabrilovich DI: All-trans-retinoic acid improves differentiation of myeloid cells and immune response in cancer patients. Cancer Res 66: 9299-9307, 2006.
7. Lathers DM, Clark JI, Achille NJ and Young MR: Phase 1B study to improve immune responses in head and neck cancer patients using escalating doses of 25 -hydroxyvitamin $\mathrm{D}_{3}$. Cancer Immunol Immunother 53: 422-430, 2004.

8. Zhou J: Arsenic trioxide: an ancient drug revived. Chin Med J (Engl) 125: 3556-3560, 2012.

9. Soignet SL, Frankel SR, Douer D, Tallman MS, Kantarjian H, Calleja E, Stone RM, Kalaycio M, Scheinberg DA, Steinherz P, et al: United States multicenter study of arsenic trioxide in relapsed acute promyelocytic leukemia. J Clin Oncol 19: 3852-3860, 2001.

10. Mann KK, Colombo M and Miller WH Jr: Arsenic trioxide decreases AKT protein in a caspase-dependent manner. Mol Cancer Ther 7: 1680-1687, 2008.

11. Rojewski MT, Baldus C, Knauf W, Thiel E and Schrezenmeier H: Dual effects of arsenic trioxide $\left(\mathrm{As}_{2} \mathrm{O}_{3}\right)$ on non-acute promyelocytic leukaemia myeloid cell lines: induction of apoptosis and inhibition of proliferation. Br J Haematol 116: 555-563, 2002.

12. Chen GQ, Shi XG, Tang W, Xiong SM, Zhu J, Cai X, Han ZG, $\mathrm{Ni} \mathrm{JH}$, Shi GY, Jia PM, et al: Use of arsenic trioxide $\left(\mathrm{As}_{2} \mathrm{O}_{3}\right)$ in the treatment of acute promyelocytic leukemia (APL): I. $\mathrm{As}_{2} \mathrm{O}_{3}$ exerts dose-dependent dual effects on APL cells. Blood 89: 3345-3353, 1997.

13. Miller WH Jr, Schipper HM, Lee JS, Singer J and Waxman S: Mechanisms of action of arsenic trioxide. Cancer Res 62: 3893-3903, 2002.

14. Li Y, Feng L, Li Y, Jiang W, Shan N and Wang X: Artesunate possesses anti-leukemia properties that can be enhanced by arsenic trioxide. Leuk Lymphoma 55: 1366-1372, 2014.

15. Thomas-Schoemann A, Batteux F, Mongaret C, Nicco C, Chéreau C, Annereau M, Dauphin A, Goldwasser F, Weill B, Lemare F, et al: Arsenic trioxide exerts antitumor activity through regulatory $\mathrm{T}$ cell depletion mediated by oxidative stress in a murine model of colon cancer. J Immunol 189: 5171-5177, 2012.

16. Michels T, Shurin GV, Naiditch H, Sevko A, Umansky V and Shurin MR: Paclitaxel promotes differentiation of myeloid-derived suppressor cells into dendritic cells in vitro in a TLR4-independent manner. J Immunotoxicol 9: 292-300, 2012.

17. Dietlin TA, Hofman FM, Lund BT, Gilmore W, Stohlman SA and van der Veen RC: Mycobacteria-induced $\mathrm{Gr}_{-1}{ }^{+}$subsets from distinct myeloid lineages have opposite effects on $\mathrm{T}$ cell expansion. J Leukoc Biol 81: 1205-1212, 2007.

18. Lechner MG, Megiel C, Russell SM, Bingham B, Arger N, Woo T and Epstein AL: Functional characterization of human $\mathrm{Cd} 33^{+}$ and $\mathrm{Cd} 11 \mathrm{~b}^{+}$myeloid-derived suppressor cell subsets induced from peripheral blood mononuclear cells co-cultured with a diverse set of human tumor cell lines. J Transl Med 9: 90, 2011.

19. Melief CJ, Scheper RJ and de Vries IJ: Scientific contributions toward successful cancer immunotherapy in The Netherlands. Immunol Lett 162: 121-126, 2014.

20. Movahedi K, Guilliams M, Van den Bossche J, Van den Bergh R, Gysemans C, Beschin A, De Baetselier P and Van Ginderachter JA: Identification of discrete tumor-induced myeloid-derived suppressor cell subpopulations with distinct T cell-suppressive activity. Blood 111: 4233-4244, 2008.

21. Albeituni SH, Ding C and Yan J: Hampering immune suppressors: therapeutic targeting of myeloid-derived suppressor cells in cancer. Cancer J 19: 490-501, 2013.

22. Shortman K and Liu YJ: Mouse and human dendritic cell subtypes. Nat Rev Immunol 2: 151-161, 2002

23. Shen J, Chen X, Wang Z, Zhang G and Chen W: Downregulation of CD40 expression contributes to the accumulation of myeloid-derived suppressor cells in gastric tumors. Oncol Lett 8: 775-780, 2014.

24. Narita Y, Wakita D, Ohkur T, Chamoto K and Nishimura T: Potential differentiation of tumor bearing mouse $\mathrm{CD} 11 \mathrm{~b}^{+} \mathrm{Gr}-1^{+}$ immature myeloid cells into both suppressor macrophages and immunostimulatory dendritic cells. Biomed Res 30: 7-15, 2009.

25. Gabrilovich D: Mechanisms and functional significance of tumour-induced dendritic-cell defects. Nat Rev Immunol 4: 941-952, 2004.

26. Hu X, Bardhan K, Paschall AV, Yang D, Waller JL, Park MA, Nayak-Kapoor A, Samuel TA, Abrams SI and Liu K: Deregulation of apoptotic factors Bcl-xL and Bax confers apoptotic resistance to myeloid-derived suppressor cells and contributes to their persistence in cancer. J Biol Chem 288: 19103-19115, 2013.

27. Young MR, Wright MA, Matthews JP, Malik I and Prechel M: Suppression of $\mathrm{T}$ cell proliferation by tumor-induced granulocyte-macrophage progenitor cells producing transforming growth factor-beta and nitric oxide. J Immunol 156: 1916-1922, 1996. 
28. Liu Y, Lai L, Chen Q, Song Y, Xu S, Ma F, Wang X, Wang J, $\mathrm{Yu}$ H, Cao X, et al: MicroRNA-494 is required for the accumulation and functions of tumor-expanded myeloid-derived suppressor cells via targeting of PTEN. J Immunol 188 5500-5510, 2012.

29. Yang L, Huang J, Ren X, Gorska AE, Chytil A, Aakre M, Carbone DP, Matrisian LM, Richmond A, Lin PC, et al: Abrogation of TGF beta signaling in mammary carcinomas recruits $\mathrm{Gr}-1^{+} \mathrm{CD} 11 \mathrm{~b}^{+}$myeloid cells that promote metastasis. Cancer Cell 13: 23-35, 2008.

30. Kusmartsev S, Nefedova Y, Yoder D and Gabrilovich DI: Antigen-specific inhibition of $\mathrm{CD} 8^{+} \mathrm{T}$ cell response by immature myeloid cells in cancer is mediated by reactive oxygen species. $\mathrm{J}$ Immunol 172: 989-999, 2004.

31. Hu X, Li B, Li X, Zhao X, Wan L, Lin G, Yu M, Wang J, Jiang X, Feng W, et al: Transmembrane $\mathrm{TNF}-\alpha$ promotes suppressive activities of myeloid-derived suppressor cells via TNFR2. J Immunol 192: 1320-1331, 2014.

32. Murai M, Turovskaya O, Kim G, Madan R, Karp CL, Cheroutre H and Kronenberg M: Interleukin 10 acts on regulatory $\mathrm{T}$ cells to maintain expression of the transcription factor Foxp3 and suppressive function in mice with colitis. Nat Immunol 10 $1178-1184,2009$.

33. Hu CE, Gan J, Zhang RD, Cheng YR and Huang GJ: Up-regulated myeloid-derived suppressor cell contributes to hepatocellular carcinoma development by impairing dendritic cell function. Scand J Gastroenterol 46: 156-164, 2011.

34. Huang B, Pan PY, Li Q, Sato AI, Levy DE, Bromberg J, Divino $\mathrm{CM}$ and Chen SH: Gr- $1^{+} \mathrm{CD} 115^{+}$immature myeloid suppressor cells mediate the development of tumor-induced $\mathrm{T}$ regulatory cells and T-cell anergy in tumor-bearing host. Cancer Res 66: 1123-1131, 2006.

35. Kujawski M, Kortylewski M, Lee H, Herrmann A, Kay H and Yu H: Stat 3 mediates myeloid cell-dependent tumor angiogenesis in mice. J Clin Invest 118: 3367-3377, 2008.

36. Trikha $\mathrm{P}$ and Carson WE 3rd: Signaling pathways involved in MDSC regulation. Biochim Biophys Acta 1846: 55-65, 2014.
37. Yu H, Pardoll D and Jove R: STATs in cancer inflammation and immunity: a leading role for STAT3. Nat Rev Cancer 9: 798-809, 2009.

38. Nefedova Y, Nagaraj S, Rosenbauer A, Muro-Cacho C, Sebti SM and Gabrilovich DI: Regulation of dendritic cell differentiation and antitumor immune response in cancer by pharmacologic-selective inhibition of the janus-activated kinase 2/signal transducers and activators of transcription 3 pathway. Cancer Res 65: 9525-9535, 2005.

39. Corzo CA, Cotter MJ, Cheng P, Cheng F, Kusmartsev S, Sotomayor E, Padhya T, McCaffrey TV, McCaffrey JC and Gabrilovich DI: Mechanism regulating reactive oxygen species in tumor-induced myeloid-derived suppressor cells. J Immunol 182: 5693-5701, 2009.

40. Vasquez-Dunddel D, Pan F, Zeng Q, Gorbounov M, Albesiano E, $\mathrm{Fu}$ J, Blosser RL, Tam AJ, Bruno T, Zhang H, et al: STAT3 regulates arginase-I in myeloid-derived suppressor cells from cancer patients. J Clin Invest 123: 1580-1589, 2013.

41. Xin H, Zhang C, Herrmann A, Du Y, Figlin R and $\mathrm{Yu} \mathrm{H}$ Sunitinib inhibition of Stat 3 induces renal cell carcinoma tumor cell apoptosis and reduces immunosuppressive cells. Cancer Res 69: 2506-2513, 2009.

42. Enioutina EY, Bareyan D and Daynes RA: A role for immature myeloid cells in immune senescence. J Immunol 186: 697-707, 2011.

43. Chalmin F, Ladoire S, Mignot G, Vincent J, Bruchard M, Remy-Martin JP, Boireau W, Rouleau A, Simon B, Lanneau D, etal: Membrane-associated Hsp72 from tumor-derived exosomes mediates STAT3-dependent immunosuppressive function of mouse and human myeloid-derived suppressor cells. J Clin Invest 120: 457-471, 2010.

44. Lee JC, Lee HY, Moon CH, Lee SJ, Lee WH, Cha HJ, Park S, Lee YH, Park HJ, Song HT, et al: Arsenic trioxide as a vascular disrupting agent: synergistic effect with irinotecan on tumor growth delay in a CT26 allograft model. Transl Oncol 6: 83-91, 2013. 